\title{
A Study of Relationships among Enterprises Based on Maximizing the Profit of Supply Chain
}

\author{
Zhenggang He $^{1}{\text { Zhengqiang } \mathrm{He}^{2} \text { Wei Liao }}^{3}$ Xiaoping Qiu ${ }^{1}$ \\ ${ }^{1}$ College of Logistics, Southwest Jiaotong University, Chengdu 610031, P.R. China \\ ${ }^{2}$ Accounting Department, Higher Training School of Hunan Finance and Economics, Changsha 410205, P.R. China \\ ${ }^{3}$ Department of E-commercial Affairs, Chengdu University of Information Technology, Chengdu 610225, P.R. China
}

\begin{abstract}
As known to us, the main profit source of supply chain is derived from the improvement of relationships among enterprises. In order to maximize the profit of the chain, longitudinal and lateral relationships among enterprises are comprehensively analyzed in this paper, with which the supply chain profit is compared. The result indicates that the cooperation is more propitious to the profit enhancement than pure competition. Thus the optimal relationship among the enterprises is established.
\end{abstract}

Keywords: Cooperation and competition, Lateral relationship, Longitudinal relationship, Relationships among enterprises

\section{Introduction}

Since 1961, J. Forrester set about the research of relationships among enterprises, it has become most important in the supply chain research, and it also represents the key point in the supply chain management now [1]. The relationship among enterprises consisted of two kinds of basic relationship: competition (noncooperation) and cooperation. Competition is the characteristic of the market economy. The competition will make the best of resources with efficiency and development. But in this competitive market, the enterprises may benefit the same or even more through cooperation than through competition [2]. The key to manage the supply chain is dealing well with the competitive and cooperative relationships among enterprises.

The longitudinal relationship between enterprises whether in upper level or lower level in supply chain (i.e. seller and purchaser) is the point of the research. A lot of researches in this field have made qualitative and quantitative analysis of it. Qualitative analysis such as Sven A. Haugland's discussion whether both parties must follow cooperative strategy and establish the long-term relation in competitive market ${ }^{[3]}$. Laura did large-scale investigation and found that competition is more efficient than cooperation ${ }^{[4]}$. Z. Lu analyzed the present conditions and further trend of relationships among enterprises and claimed that it will experience four stages, from the traditional transaction to strategic cooperation relationship ${ }^{[5]}$. J. Yao deemed that the traditional supply chain relationship based on rights is a competitive relation which is merely to win or not, and strategic cooperation relationship based on trust is a typical win-win relationship ${ }^{[6]}$. The development of enterprise relationship was divided into three stages by Z.X. Chen from the historical angle, from the traditional enterprise relation, logistics to strategy relationship ${ }^{[7]}$. Y.L. Sun holds that the new strategy alliance requests the enterprises adjust the view of value, and establish competitive and cooperative relationship among enterprises to win sustainable advantages ${ }^{[8]}$. Y. Zhang did research on it with the theory of transaction cost. In her opinion, enterprises relationships are directly affected by the factor of commitment, dependence and professional investment etc, and this forms different kinds of relationships which decide success or failure ${ }^{[9]}$. Quantitative analysis are as follows: M. M. Zhong analyzed the limited and unlimited transaction of enterprises in upper and lower level on supply chain, and compared the supply chain benefits with these two strategies which are full cooperation and inadequate cooperation $^{[10]}$. D.M. Song established a model of enterprises' cooperation and competition, and adopted "replication" in biology to emulate and participate in human' study and adjustment. The evolved stable strategy was used to describe a long period of evolution of enterprises' cooperation and competition ${ }^{[11]}$. W.B. Yao made use of Game Theory to analyze the relationship of the upper and lower supply chain in complete free competitive market, complete monopolized market and monopolized competitive market. He opines that enterprises compete more under complete free competitive market and complete monopolized market, but enterprises cooperate more under monopolized competitive market ${ }^{[12]}$.Susan X. Li analyzed the selling price of seller and economic ordering quantity of purchaser under the circumstance of cooperation and non-cooperation ${ }^{[13]}$.

Comparatively, the research of competition and cooperation relationships among enterprises which are in the same position on different supply chain (lateral relationship) is few. Most of the scholars agreed that enterprises should cooperate with each other in longitudinal relationship, but it is not clear that between cooperation and competition which takes the lead in lateral relationship. And it didn't discuss which basic strategy should be taken while enterprises are facing both 
lateral relationship and longitudinal relationship. This paper will discuss the lateral and longitudinal relationship among supply chain enterprises, and compare the supply chain profits on these two relationship so that we can establish the optimal relationship based on the maximal profit.

\section{Model Assumptions}

We suppose that one seller sells the same kind of product to the two purchasers placed in the same market (figure 1 shows below). The seller determines its price and the purchaser decides the purchasing amount. The seller has its own stack of storage to satisfy customers' needs. And lack of storage is not allowed. The purchasers also have its' own storage. And lack of storage is not allowed either, The biggest investment of purchaser is $C_{0}$.

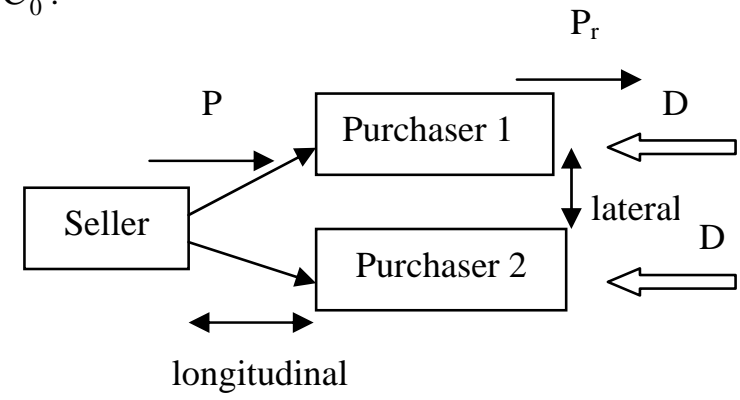

Fig.1: The relationship between seller and purchaser.

The model definition is as follows:

The selling price of the seller is $P$, the selling price of the purchaser is $P_{r}$.For the sack of convenience, we suppose the relationship between these two prices is linear, that is $P_{r}=k P, k \geq 1 . L$ represents the net profits of the seller which is the percent of the sales volume .The decision variable of the seller is $P$.The purchaser' demand is $D$ and suppose that it is the reduction function of the selling prices, $D=\alpha P^{-\beta}, \alpha>0,0 \leq \beta \leq 1 . Q$ represents a purchasing amount of every purchaser and it is the decision variable of the seller. $C_{o s}$ is preparation cost of the seller, $C_{o b}$ is the unit ordering cost of the purchaser. $h_{s}, h_{b}$ is the percent of the selling price $\mathrm{P}$. $h_{s} P$ is the storage cost of the seller and $h_{b} P$ is the storage cost of the purchaser. $C_{s}$ is the total cost of the seller and $C_{b}$ is the total cost of the purchaser . $\sum C_{b}$ is the sum of the purchasing cost of two purchasers, $\sum C_{b}=2 C_{b} . G_{s}$ is the profits of the seller and $G_{b}$ is the profits of the purchaser . $\sum G_{b}$ is the sum of the profits of two purchasers, $\sum G_{b}=2 G_{b} . G$ is the total profits of the supply chain , $G=G_{s}+\sum G_{b}$.

In general, there are four basic relationships among seller and purchaser. First of all, there is non-cooperation between seller and purchaser and non-cooperation among purchasers. (non-cooperation in both lateral and longitudinal relationship). Secondly there is non-cooperation between seller and purchaser and cooperation among purchasers. (non-cooperation in longitudinal relationship but cooperation in lateral relationship). Then, there is cooperation between seller and purchaser and non-cooperation among purchasers (cooperation in longitudinal relationship but noncooperation in lateral relationship). The fourth relationship is that there is cooperation between seller and purchaser and cooperation among purchasers (cooperation in both longitudinal and lateral relationship). The cooperation discussed in this paper is mainly in stock and purchase .Comparing the total profits of supply chain under these four situations, we can get the optimal relationship between sellers and purchasers based on the maximal profit.

\section{The Model Establishment}

The biggest profit of the supply chain $G$, the optimal selling prices $P^{*}$ and economic ordering quantity $Q^{*}$ under these four situations are discussed by establishing the model.

\subsection{Non-cooperation in both lateral and longitudinal relationship}

It is a typical two stages Game Theory between seller and purchaser. The seller announces its selling price first and then the purchaser decides its purchasing quantity. Because of non-cooperation among purchasers, it is two independent two stages Game Theory.

The profit of one purchaser is:

$$
G_{b}=\left(P_{r}-P\right) D-\frac{D}{Q} c_{o b}-\frac{Q}{2} h_{b} P
$$

The cost of it is:

$$
C_{b}=P D+\frac{D}{Q} C_{o b}+\frac{Q}{2} h_{b} P
$$

The EOQ is:

$$
Q^{*}=\sqrt{\frac{2 c_{o b} D}{h_{b} P}}=\sqrt{\frac{2 c_{o b} \alpha P^{-\beta-1}}{h_{b}}}
$$

The maximal profit of one purchaser is:

$\max G_{b}=\left(P_{r}-P\right) D-\sqrt{2 c_{o b} h_{b} D P}$

The profit of the supplier is : 


$$
G_{s}=L P D-\frac{D}{Q} C_{o s}-\frac{Q}{2} h_{s} P
$$

Get (1)into (2), we can get :

$$
G_{s}=L \alpha P^{1-\beta}-\frac{1}{2} \sqrt{2 \alpha P^{1-\beta} c_{o b} h_{b}}\left(\frac{c_{o s}}{c_{o b}}+\frac{h_{s}}{h_{b}}\right)
$$

Because of $C_{b} \leq C_{0}$, we can get $P D+\sqrt{2 c_{o b} h_{b} D P} \leq C_{0}$

We can get the optimal selling price and EOQ.:

$$
P^{*}=\left[\frac{c_{o b} h_{b}+C_{0}-\sqrt{c_{o b} h_{b}\left(c_{o b} h_{b}+2 C_{0}\right)}}{\alpha}\right]^{1 / 1-\beta}
$$

(the process of deduce in Appendix 1)

$$
Q^{*}=\sqrt{\frac{2 \alpha c_{o b}}{h_{b} P^{*(1+\beta)}}}
$$

The maximal profit of the supply chain:

$$
\begin{aligned}
& \max G=2 \max \left(G_{b}+G_{s}\right)=2(k-1+L) \alpha P^{*(1-\beta)} \\
& -\sqrt{2 \alpha P^{*(1-\beta)} c_{o b} h_{b}}\left(\frac{c_{o b}+c_{o s}}{c_{o b}}+\frac{h_{b}+h_{s}}{h_{b}}\right)
\end{aligned}
$$

\subsection{Non-cooperation between seller and purchaser and cooperation among purchasers}

When two purchasers cooperate, we can merge these two demands and purchase to seller in one purchaser. Because of non-cooperation between seller and purchaser, the seller announces its selling price first and then the purchaser decides its purchasing quantity.

The total profits of two purchasers are:

$\sum G_{b}=2 D\left(P_{r}-P\right)-\frac{2 D}{Q} C_{o b}-\frac{Q}{2} h_{b} P$

The total costs of two purchasers are:

$$
\sum C_{b}=2 P D+\frac{2 D}{Q} C_{o b}+\frac{Q}{2} h_{b} P
$$

The EOQ is:

$$
Q^{*}=\sqrt{\frac{4 c_{o b} D}{h_{b} P}}=\sqrt{\frac{4 c_{o b} \alpha P^{-\beta-1}}{h_{b}}}
$$

The profits of the supplier are:

$$
G_{s}=2 L P D-\frac{2 D}{Q} c_{o s}-\frac{Q}{2} h_{s} P
$$

Get (3) into (4), we can get:

$$
G_{s}=2 L \alpha P^{1-\beta}-\sqrt{\alpha P^{1-\beta} c_{o b} h_{b}}\left(\frac{c_{o s}}{c_{o b}}+\frac{h_{s}}{h_{b}}\right)
$$

Because of $\sum C_{b} \leq 2 C_{0}$, we can get $P D+\frac{D}{Q} c_{o b}+\frac{Q}{4} h_{b} P=P D+\sqrt{c_{o b} h_{b} D P} \leq C_{0}$.

Through deducing, we can get the optimal selling price and EOQ.:

$$
\begin{gathered}
P^{*}=\left[\frac{c_{o b} h_{b}+2 C_{0}-\sqrt{c_{o b} h_{b}\left(c_{o b} h_{b}+4 C_{0}\right)}}{2 \alpha}\right]^{1 / 1-\beta} \\
Q^{*}=\sqrt{\frac{4 \alpha C_{o b}}{h_{b} P^{*(1+\beta)}}}
\end{gathered}
$$

The maximal profit of the supply chain:

$$
\begin{aligned}
\max G & =\sum G_{b}+G_{s}=2(k-1+L) \alpha P^{*(1-\beta)} \\
& -\sqrt{\alpha P^{*(1-\beta)} C_{o b} h_{b}}\left(\frac{c_{o b}+c_{o s}}{c_{o b}}+\frac{h_{b}+h_{s}}{h_{b}}\right)
\end{aligned}
$$

\subsection{Cooperation between seller and purchaser and non-cooperation among purchasers}

The seller and the purchaser cooperate and decide the selling prices and purchasing quantity in order to get biggest profits. Because of non-cooperation among purchasers, it forms two independent supply chains between seller and two purchasers.

The total profits of the sell and one purchaser is:

$$
\begin{aligned}
& G=(k+L-1) P D-\frac{D}{Q}\left(c_{o s}+c_{o b}\right)-\frac{Q}{2} P\left(h_{s}+h_{b}\right) \\
& Q^{*}=\sqrt{\frac{2 D\left(c_{o b}+c_{o s}\right)}{\left(h_{b}+h_{s}\right) P}}=\sqrt{\frac{2 \alpha\left(c_{o b}+c_{o s}\right)}{\left(h_{b}+h_{s}\right) P^{1+\beta}}}
\end{aligned}
$$

Get (6) into (5), we can get:

$$
G=(k+L-1) \alpha P^{1-\beta}-\sqrt{2\left(c_{o b}+c_{o s}\right)\left(h_{b}+h_{s}\right) \alpha P^{1-\beta}}
$$

When $\frac{\partial G}{\partial P}=0$, we can get the optimal selling price of the supply chain:

$$
P^{*}=\left[\frac{\left(c_{o b}+c_{o s}\right)\left(h_{b}+h_{s}\right)}{2 \alpha(k+L-1)^{2}}\right]^{1 / 1-\beta}
$$

The maximal profit of the supply chain: $\max G=2(k+L-1) \alpha P^{*(1-\beta)}-2 \sqrt{2\left(c_{o b}+c_{o s}\right)\left(h_{b}+h_{s}\right) \alpha P^{*(1-\beta)}}$

\subsection{Cooperation between seller and purchaser and cooperation among purchasers}

When two purchases cooperate and merge purchasing quantity, the seller cooperates with one purchaser to decide the selling prices and purchasing quantity.

The total profits of the seller and two purchasers is: 


$$
\begin{aligned}
& G=2(k+L-1) P D-\frac{2 D}{Q}\left(c_{o s}+c_{o b}\right)-\frac{Q}{2} P\left(h_{s}+h_{b}\right) \\
& Q^{*}=\sqrt{\frac{4 D\left(c_{o b}+c_{o s}\right)}{\left(h_{b}+h_{s}\right) P}}=\sqrt{\frac{4 \alpha\left(c_{o b}+c_{o s}\right)}{\left(h_{b}+h_{s}\right) P^{1+\beta}}}
\end{aligned}
$$

Get (8) into (7), we can get:

$$
G=2(k+L-1) \alpha P^{1-\beta}-2 \sqrt{\left(c_{o b}+c_{o s}\right)\left(h_{b}+h_{s}\right) \alpha P^{1-\beta}}
$$

When $\frac{\partial G}{\partial P}=0$, we can get the optimal selling price of the supplier:

$$
P^{*}=\left[\frac{\left(c_{o b}+c_{o s}\right)\left(h_{b}+h_{s}\right)}{4 \alpha(k+L-1)^{2}}\right]^{1 / 1-\beta}
$$

The maximal profit of the supply chain:

$$
\begin{aligned}
\max G= & 2(k+L-1) \alpha P^{*(1-\beta)} \\
& -2 \sqrt{\left(c_{o b}+c_{o s}\right)\left(h_{b}+h_{s}\right) \alpha P^{*(1-\beta)}}
\end{aligned}
$$

\section{The model analysis}

We can conclude form the below four situation .we can get tab.1, tab.2, tab.3 (at the last page-P6).

From Tab.1, we can get:

$P_{1}^{*}<P_{2}^{*}$ (the process of deduce in Appendix 2), $P_{3}^{*}<P_{1}^{*}{ }^{[13]}, P_{3}^{*}>P_{4}^{*}$ and $P_{4}^{*}<P_{3}^{*}<P_{1}^{*}<P_{2}^{*}$

From Tab.2, we can get:

$$
Q_{4}^{*}>Q_{3}^{*}>Q_{1}^{*}>Q_{2}^{*}
$$

From Tab.3, we can get:

$$
\max G_{1}<\max G_{3} \text {. }
$$

As the same, $\max G_{2}<\max G_{4}, \max G_{1}<\max G_{2}$ (the process of deduce in Appendix 3), $\max G_{3}<\max G_{4}$ (the process of deduce in Appendix 4). So the results are: $\max G_{1}<\max G_{2}<\max G_{4}, \max G_{1}<\max G_{3}<\max G_{4}$.

\section{Conclusions}

We can conclude based on the model analysis:

(1) $P_{4}^{*}<P_{3}^{*}<P_{1}^{*}<P_{2}^{*}, Q_{4}^{*}>Q_{3}^{*}>Q_{1}^{*}>Q_{2}^{*}$. We can conclude it from these situations that when cooperation is in both lateral and longitudinal relationship, we can get the lowest selling price and biggest purchasing amount. when non-cooperation is in longitudinal and cooperation in lateral relationship, we can get the highest selling price and smallest purchasing amount .

(2) $\max G_{1}<\max G_{2}, \max G_{1}<\max G_{3}$ 。That is to say, the profit of the supply chain which is under cooperation is bigger than which is under competition whatever it is lateral or longitudinal relationship.

(3) $\max G_{4}$ is the biggest profit, which means the profit of the supply chain is biggest when the chain is both lateral and longitudinal cooperation.
(4) If enterprises should choose one, it lies in parameter $C_{0}, k, L, \alpha, \beta, c_{o s}, c_{o b}, h_{s}, h_{b}$.

(5) The pattern of the lateral cooperation and the longitudinal cooperation is different. The longitudinal cooperation increase profit through storage, while the lateral cooperation through merging purchasing quantity.

The result indicates that the cooperation is more propitious to the profit enhancement rather than complete competition. So the supply chain of enterprises should establish the cooperation relationship.

\section{Reference}

[1] Y.S. Jiang, Y.R.Chen, Y. Pu, Study on supply chain relationship coordination management, Journal of Chongqing Jiaotong University, 24(6):133-136, 2005.

[2] R.X. Jia, Y. Liu, Study on the Enterprise Cooperation, Journal of Beijing Administrative College, 5:30-35,2004.

[3] SVEN. HAUGLAND,Cooperative relationships in competitive markets, Journal of Socio-Economics, 25(3):359-371,2003.

[4] Laura B. Forker, Peter Stannack, Cooperation versus competition: do buyers and suppliers really see eye-to-eye? European Journal of Purchasing \& Supply Management, pp. 31-40, July 2000.

[5] Z.Lu, Q.H.Bai, Analysis and research on strategic cooperative partnership of supply chain, Journal of Hefei University of Technolog, 18(2):10-15, 2004.

[6] J.Yao, Study on the Supply Chain Strategic Partnership Relationship. Value Engineering, 5: 28-30, 2003.

[7] Z.X.Chen, S.H. Ma. Collaborative Relationships in Supply Chain, Nankai Business Review, 2:56-59, 2001.

[8] Y.L. Sun, S.F. Peng, Study on the Evolutionary Module of Strategic Alliance among Enterprises. Journal of Yunnan University of Finance and Economics, 2(2):92-96, 2005.

[9] H. Zhang, C.L.ZHANG ,P.Q. Huang, Research Reviews of Inter-firm Relationships Based on Transaction Cost Economic Theory ,Journal of Shanghai Maritime University, 23(3):39-43,2002.

[10] M.M. Zhong, Q.P. Wu, Analysis of Enterprises Cooperation in Supply Chain Based on Game Theory, Journal of Hehai University Changzhou, 19(1):39-42,2005.

[11]D.M. Song, Y.N. Zhang, An Analyzes of Evolutionary Stable Strategy in Corporation Co-petition Games, Value Engineering, 7:44-46,2004.

[12] W.B.Yao, G.H. Wang, W.Y. Ding , China Logistics \& Purchasing, 20:38-40, 2003.

[13] Susan X. Li, Zhimin Huang, Allan Ashley, Improving buyer-seller system cooperation through 
inventory control, International Journal of Production Economics, 43: 37-46,1996.

\section{Appendix 1}

If when $P D+\sqrt{2 c_{o b} h_{b} D P}=C_{0}$, The supply chain gets maximum profit.

$$
\begin{aligned}
& \text { Provided } P D=\alpha P^{1-\beta}=t^{2}, \\
& \text { then } t^{2}+\sqrt{2 c_{o b} h_{b}} t-C_{0}=0 \\
& t=\sqrt{\alpha P^{1-\beta}}=\frac{-\sqrt{2 c_{o b} h_{b}}+\sqrt{2 c_{o b} h_{b}+4 C_{0}}}{2}, \\
& P^{*}=\left[\frac{c_{o b} h_{b}+C_{0}-\sqrt{c_{o b} h_{b}\left(c_{o b} h_{b}+2 C_{0}\right)}}{\alpha}\right]^{1 / 1-\beta}
\end{aligned}
$$

\section{Appendix 2}

To compare $P_{1}^{*}$ and $P_{2}^{*}$, equal to compare $\frac{c_{o b} h_{b}+C_{0}-\sqrt{c_{o b} h_{b}\left(c_{o b} h_{b}+2 C_{0}\right)}}{\alpha}$ and $\frac{c_{o b} h_{b}+2 C_{0}-\sqrt{c_{o b} h_{b}\left(c_{o b} h_{b}+4 C_{0}\right)}}{2 \alpha}$, also equal to $c_{o b} h_{b}-\sqrt{c_{o b} h_{b}\left(c_{o b} h_{b}+2 C_{0}\right)}$ and $\frac{1}{2} c_{o b} h_{b}-\frac{1}{2} \sqrt{c_{o b} h_{b}\left(c_{o b} h_{b}+4 C_{0}\right)}$.

$$
\begin{gathered}
P_{1}^{*}-P_{2}^{*}=\frac{1}{2} c_{o b} h_{b}+\frac{1}{2} \sqrt{c_{o b} h_{b}\left(c_{o b} h_{b}+4 C_{0}\right)} \\
-\sqrt{c_{o b} h_{b}\left(c_{o b} h_{b}+2 C_{0}\right)}=\frac{1}{2} \sqrt{c_{o b} h_{b}}\left(\sqrt{c_{o b} h_{b}}\right. \\
\left.+\sqrt{c_{o b} h_{b}+4 C_{0}}-2 \sqrt{c_{o b} h_{b}+2 C_{0}}\right)
\end{gathered}
$$

Because of $c_{o b} h_{b}<<C_{0}$, we can get

$$
\frac{1}{2} \sqrt{c_{o b} h_{b}}\left(\sqrt{c_{o b} h_{b}}+\sqrt{4 C_{0}}-2 \sqrt{2 C_{0}}\right)
$$

$\approx \frac{1}{2} \sqrt{c_{o b} h_{b}}\left(\sqrt{4 C_{0}}-\sqrt{8 C_{0}}\right)<0$

So we can get $P_{1}^{*}<P_{2}^{*}$.

\section{Appendix 3}

$$
\begin{gathered}
\max G_{2}-\max G_{1}= \\
{\left[2(k-1+L) \alpha P_{2}^{*(1-\beta)}-\sqrt{\alpha P_{2}^{*(1-\beta)} c_{o b} h_{b}}\left(\frac{c_{o b}+c_{o s}}{c_{o b}}+\frac{h_{b}+h_{s}}{h_{b}}\right)\right]}
\end{gathered}
$$

$$
\begin{aligned}
& -\left[2(k-1+L) \alpha P_{1}^{*(1-\beta)}-\sqrt{2 \alpha P_{1}^{*(1-\beta)} c_{o b} h_{b}}\left(\frac{c_{o b}+c_{o s}}{c_{o b}}+\frac{h_{b}+h_{s}}{h_{b}}\right)\right] \\
= & 2(k-1+L)\left[\alpha P_{2}^{*(1-\beta)}-\alpha P_{1}^{*(1-\beta)}\right]
\end{aligned}+
$$

Because of $P_{1}^{*}<P_{2}^{*}$, then

$$
2(k-1+L)\left[\alpha P_{2}^{*(1-\beta)}-\alpha P_{1}^{*(1-\beta)}\right]>0 \text {. }
$$

We can get $\max G_{2}>\max G_{1}$.

\section{Appendix 4}

$$
\begin{aligned}
& \max G_{3}-\max G_{4} \\
& =2(k+L-1) \alpha\left[P_{3}^{*(1-\beta)}-P_{4}^{*(1-\beta)}\right] \\
& \quad+2 \sqrt{\left(c_{o b}+c_{o s}\right)\left(h_{b}+h_{s}\right) \alpha P_{4}^{*(1-\beta)}} \\
& =
\end{aligned}
$$

$2(k+L-1)\left[\frac{\left(c_{o b}+c_{o s}\right)\left(h_{b}+h_{s}\right)}{2(k+L-1)^{2}}-\frac{\left(c_{o b}+c_{o s}\right)\left(h_{b}+h_{s}\right)}{4(k+L-1)^{2}}\right]$
$+2 \sqrt{\frac{\left(c_{o b}+c_{o s}\right)^{2}\left(h_{b}+h_{s}\right)^{2}}{4(k+L-1)^{2}}}-2 \sqrt{\frac{2\left(c_{o b}+c_{o s}\right)^{2}\left(h_{b}+h_{s}\right)^{2}}{2(k+L-1)^{2}}}<0$.

So we can get $\max G_{3}<\max G_{4}$. 


\begin{tabular}{|c|c|c|c|}
\hline \multicolumn{1}{|c|}{} & \multicolumn{2}{|c|}{ Longitudinal } & Relationship \\
\cline { 3 - 4 } & $\begin{array}{c}\text { Non- } \\
\text { Lateral } \\
\text { Relationship }\end{array}$ & $P_{1}^{*}=\left[\frac{c_{o b} h_{b}+C_{0}-\sqrt{C_{o b} h_{b}\left(c_{o b} h_{b}+2 C_{0}\right)}}{\alpha}\right]^{1 / 1-\beta}$ & $P_{3}^{*}=\left[\frac{\left(c_{o b}+c_{o s}\right)\left(h_{b}+h_{s}\right)}{2 \alpha(k+L-1)^{2}}\right]^{1 / 1-\beta}$ \\
\cline { 2 - 4 } & Cooperation & $P_{2}^{*}=\left[\frac{c_{o b} h_{b}+2 C_{0}-\sqrt{C_{o b} h_{b}\left(c_{o b} h_{b}+4 C_{b}\right)}}{2 \alpha}\right]^{1 / 1-\beta}$ & $P_{4}^{*}=\left[\frac{\left(c_{o b}+c_{o s}\right)\left(h_{b}+h_{s}\right)}{4 \alpha(k+L-1)^{2}}\right]^{1 / 1-\beta}$ \\
\hline
\end{tabular}

Tab.1: The optimal selling price of supplier from each situation.

\begin{tabular}{|c|c|c|c|}
\hline \multirow{2}{*}{} & \multicolumn{2}{|c|}{ Longitudinal Relationship, } \\
\cline { 3 - 4 } $\begin{array}{c}\text { Lateral } \\
\text { Relationship }\end{array}$ & $\begin{array}{c}\text { Non- } \\
\text { cooperation }\end{array}$ & $Q_{1}^{*}=2 \sqrt{\frac{2 c_{o b} \alpha}{h_{b} P_{1}^{*(\beta+1)}}}$ & $Q_{3}^{*}=2 \sqrt{\frac{2 \alpha\left(c_{o b}+c_{o s}\right)}{\left(h_{b}+h_{s}\right) P_{3}^{*(\beta+1)}}}$ \\
\cline { 2 - 4 } & $\begin{array}{c}\text { Cooper } \\
\text { ation }\end{array}$ & $Q_{2}^{*}=\sqrt{\frac{4 c_{o b} \alpha}{h_{b} P_{2}^{*(\beta+1)}}}$ & $Q_{4}^{*}=\sqrt{\frac{4 \alpha\left(c_{o b}+c_{o s}\right)}{\left(h_{b}+h_{s}\right) P_{4}^{*(\beta+1)}}}$ \\
\hline
\end{tabular}

Tab.2: The purchasing quantity from each situation.

\begin{tabular}{|c|c|c|c|}
\hline & \multicolumn{2}{|c|}{ Longitudinal Relationship, } \\
\hline & & Non-cooperation & Cooperation \\
\hline \multirow{2}{*}{$\begin{array}{l}\text { Lateral } \\
\text { Relationshi } \\
\text { p }\end{array}$} & $\begin{array}{c}\text { Non- } \\
\text { cooperation }\end{array}$ & $\begin{array}{l}\max G_{1}=2(k-1+L) \alpha P_{1}^{*(1-\beta)} \\
-\sqrt{2 \alpha P_{1}^{*(1-\beta)} c_{o b} h_{b}}\left(\frac{c_{o b}+c_{o s}}{c_{o b}}+\frac{h_{b}+h_{s}}{h_{b}}\right)\end{array}$ & $\begin{array}{l}\max G_{3}=2(k+L-1) \alpha P_{3}^{*(1-\beta)} \\
-2 \sqrt{2\left(c_{o b}+c_{o s}\right)\left(h_{b}+h_{s}\right) \alpha P_{3}^{*(1-\beta)}}\end{array}$ \\
\hline & $\begin{array}{l}\text { Cooper } \\
\text { ation }\end{array}$ & $\begin{array}{l}\max G_{2}=2(k-1+L) \alpha P_{2}^{*(1-\beta)} \\
-\sqrt{\alpha P_{2}^{*(1-\beta)} c_{o b} h_{b}}\left(\frac{c_{o b}+c_{o s}}{c_{o b}}+\frac{h_{b}+h_{s}}{h_{b}}\right)\end{array}$ & $\begin{array}{l}\max G_{4}=2(k+L-1) \alpha P_{4}^{*(1-\beta)} \\
-2 \sqrt{\left(c_{o b}+c_{o s}\right)\left(h_{b}+h_{s}\right) \alpha P_{4}^{*(1-\beta)}}\end{array}$ \\
\hline
\end{tabular}

Tab. 3: The biggest profit of supply chain from each situation. 